\title{
Reduced azole susceptibility of oral isolates of Candida albicans from HIV-positive patients and a derivative exhibiting colony morphology variation
}

\author{
Paul J. Gallagher, ${ }^{1}$ Désirée E. Bennett, ${ }^{2}$ Martin C. Henman, ${ }^{1}$ Ronnie J. Russell, ${ }^{2}$ \\ Stephen R. Flint, ${ }^{3}$ Diarmuid B. Shanley ${ }^{3}$ and David C. Coleman ${ }^{3 *}$ \\ ${ }^{1}$ Trinity College, Department of Pharmacology, School of Pharmacy, University of Dublin, 18 Shrewsbury Road, \\ Dublin 4, Republic of Ireland \\ ${ }^{2}$ Trinity College, Department of Microbiology, Moyne Institute, University of Dublin, Dublin 2, Republic of Ireland \\ ${ }^{3}$ Trinity College, Department of Oral Medicine and Pathology, School of Dental Science, University of Dublin, \\ Dental School Office, 30 Westland Row, Dublin 2, Republic of Ireland
}

(Received 12 March 1992; revised 11 June 1992; accepted 18 June 1992)

\begin{abstract}
Approximately 50\% (15/28) of a selection of oral isolates of Candida albicans from separate individuals infected with the human immunodeficiency virus (HIV) exhibited low susceptibility to ketoconazole as determined by hyphal elongation assessment. Nine of these isolates exhibited colony morphology variation or switching at $37^{\circ} \mathrm{C}$, of which six expressed low ketoconazole susceptibility. To determine whether colony morphology variation could give rise to derivatives with reduced azole susceptibility, several high-frequency switching variants of three HIVpatient isolates were recovered and assessed. All but one of the variants expressed similar azole susceptibility profiles to their respective parental strains. However, the $C$. albicans derivative 132ACR expressed significantly reduced susceptibility to ketoconazole in comparison to its parental strain 132A. In whole cells, on the basis of total growth the switched derivative 132ACR was markedly less susceptible than its parental isolate 132A to ketoconazole at $10 \mu \mathrm{M}$. A much smaller difference was observed with fluconazole at $10 \mu \mathrm{M}$, with the switched derivative 132ACR exhibiting a threefold lower susceptibility compared with the parental isolate 132A. The incorporation of $\left[{ }^{14} \mathrm{C}\right.$ acetate in control and azole-treated cells of both organisms was higher for the parental strain. When cell lysates of strain $132 \mathrm{~A}$ and its derivative $132 \mathrm{ACR}$ were incubated with $\left[{ }^{14} \mathrm{C} / \mathrm{mevalonic}\right.$ acid and ketoconazole, the $\mathrm{IC}_{50}$ for ${ }^{14} \mathrm{C}$-label incorporation into $\mathrm{C}$-4 demethyl sterols was fivefold higher for lysates of the switched derivative $132 \mathrm{ACR}$ compared with those of the parental strain $132 \mathrm{~A}$. With fluconazole the $\mathrm{IC}_{50}$ value for the derivative 132ACR was 25-fold higher than for strain 132A. The 14-sterol demethylase of the switched derivative 132ACR was possibly less sensitive to azole inhibition than that of the enzyme of strain 132A. These studies indicated that colony morphology variation in vitro can generate derivatives with stable, reduced azole susceptibility without prior exposure to azoles.
\end{abstract}

\section{Introduction}

Oropharyngeal candidosis caused by Candida albicans is one of the most common manifestations of opportunistic infection among individuals infected with the human immunodeficiency virus $\left(\mathrm{HIV}^{+}\right)$and patients with acquired immunodeficiency syndrome (AIDS; Gottlieb et al., 1981 ; Klein et al., 1984; Holmberg \& Meyer, 1986; Tavitian et al., 1986a; Phelan et al., 1987; Redfield \& Burke, 1988; Syrjanen et al., 1988; Samaranayake \&

- Author for correspondence. Tel. +35317021814 ; fax +3531 6799294.
Holmstrup, 1989; Mandal, 1989; Samaranayake, 1990). Persistence of oral candidosis in these individuals and relapse following treatment with antifungal drugs is very common (Glatt et al., 1988; Samaranayake \& Holmstrup, 1989; Larsen,1990). This is thought to be due to a variety of causes, including the underlying immunodeficiency, poor patient compliance, azole hepatotoxicity, gastrointestinal intolerance and the development of decreased drug susceptibility, and, in the case of the imidazole ketoconazole, poor absorption in the presence of achlorhydria (Tavitian et al., 1986a; Korting et al., 1988; Epstein, 1990; Larsen, 1990; Fox et al., 1991). 
The $N$-substituted imidazole or triazole antifungal antibiotics, including ketoconazole and fluconazole, are commonly prescribed for the treatment of oral candidosis in $\mathrm{HIV}^{+}$and AIDS patients (Van Den Bossche et al., 1990). Azoles probably act by inhibiting cytochrome $P$ 450-dependent 14-sterol demethylase, an important enzyme in ergosterol biosynthesis in fungi (Borgers, 1980). Ergosterol is the main sterol found in Candida species and forms a vital constituent of cellular membranes. The depletion of ergosterol and the resulting accumulation of 14-methylated sterols disrupts membrane structure and function, resulting in inhibition of growth (Van Den Bossche et al., 1988).

Many oral isolates $(\geq 30 \%)$ of $C$. albicans from Irish $\mathrm{HIV}^{+}$and AIDS patients exhibit colony morphology variation at $37^{\circ} \mathrm{C}$ on primary isolation, and these occasionally give rise to additional colony variants on subculture (D. C. Coleman \& D. E. Bennett, unpublished data). Preliminary studies indicated that some of these variant or switched derivatives exhibited decreased susceptibility to azole antifungals in vitro, as determined by agar plate dilution and hyphal elongation assessment tests (Gallagher et al., 1991). Colony morphology variation is a common feature among isolates of both $C$. albicans and other Candida species (Soll et al., 1987; Rikkerink et al., 1988; Odds \& Merson-Davies, 1989; Soll, 1989; Suzuki et al., 1991; Wickes et al., 1991). Certain switched $C$. albicans derivatives can exhibit a variety of altered morphological, physiological, cell surface and genetic characteristics, including adhesion to epithelial cells, antigenicity, hypha formation, cell size, growth rate, karyotype and genotype variation and decreased susceptibility to the antifungal drugs nystatin, amphotericin B, miconazole nitrate and 5-fluorocytosine (Slutsky et al., 1985; Merz et al., 1988; Soll, 1989; Ghannoum et al., 1990; Iwaguchi et al., 1990; Rustchenko-Bulgac et al., 1990; Rustchenko-Bulgac, 1991; McEachern \& Hicks, 1991). In HIV ${ }^{+}$and AIDS patients, where the levels of oral C. albicans can be very high (Tylenda et al., 1989), this variability could allow the generation of altered forms which are better adapted for survival in the oral cavity. Recently Odds \& MersonDavies (1989) have shown that nutrient depletion in vitro can induce Candida isolates to form colony morphology variants. A parallel situation in vivo in the oral cavities of HIV-infected individuals could result in densely packed Candida cells depleting available nutrients, resulting in switching. Furthermore, the comprehensive therapeutic regimes often undertaken in $\mathrm{HIV}^{+}$and AIDS patients could possibly also act as a trigger for switching. Thus, phenotypic switching in vivo may lead to the generation of substantial numbers of variants possessing altered phenotypes and/or genotypes, some of which may be better suited to survive in the oral cavity.
The aims of the present study were (1) to compare azole susceptibilities among a selection of $C$. albicans oral isolates from Irish $\mathrm{HIV}^{+}$patients and from healthy carriers, and (2) to investigate the basis of significantly decreased azole susceptibility exhibited by one particular switched derivative generated from an azole-susceptible parental isolate.

\section{Methods}

Strains, derivatives and culture conditions. C. albicans isolates were routinely grown on Potato Dextrose Agar medium (PDA, Oxoid) at $\mathrm{pH} 5 \cdot 6$, supplemented with $0.4 \%$ (w/v) Noble agar (Difco) at $37^{\circ} \mathrm{C}$. For liquid culture, isolates were routinely grown in Yeast Peptone Dextrose Broth [YPD; per litre: $10 \mathrm{~g}$ yeast extract (Oxoid), $20 \mathrm{~g}$ peptone (Difco), $20 \mathrm{~g}$ glucose, $\mathrm{pH} 5.5$ ] at $37^{\circ} \mathrm{C}$ in an orbital incubator (Gallenkamp) set at 180 r.p.m. For ${ }^{14} \mathrm{C}$-labelling of whole $C$. albicans cells using [U-14 C]acetate, YEPD (YPD containing 5 g glucose $^{-1}$ ) was used as the liquid culture medium.

C. albicans isolates and derivatives were identified on the basis of positive germ-tube tests following growth in $2.0 \mathrm{ml}$ fresh human serum at $37^{\circ} \mathrm{C}$ for $2 \mathrm{~h}$, by their ability to produce hyphae and chlamydospores on rice-agar-Tween agar (RAT agar; bioMérieux) and by their carbohydrate- and nitrogen-source assimilation patterns using the ID 32C yeast identification system (API Systems).

Forty oral isolates of $C$. albicans were included in this study. These were recovered from saliva or from swab specimens of the mid-dorsum of the tongue by plating on PDA alone and PDA supplemented with the dye phloxine $\mathrm{B}\left(5 \mu \mathrm{g} \mathrm{ml}^{-1} ; \mathrm{PDAB}\right)$ followed by incubation at $37^{\circ} \mathrm{C}$ for $48 \mathrm{~h}$. Differential staining of portions or sectors of oral C. albicans colonies with phloxine $\mathrm{B}$ following growth on PDAB agar allowed the detection of some clinical isolates which exhibited colony morphology variation (Anderson \& Soll, 1987; Odds \& Merson-Davies, 1989). For primary isolation purposes, PDA and PDAB plates were supplemented with chloramphenicol $\left(50 \mu \mathrm{g} \mathrm{ml}^{-1}\right)$. Control isolates were oral-carriage strains recovered from saliva samples of 12 healthy individuals with no known predisposition to immunosuppression. At sampling none of ii ese individuals had any clinical signs of oral candidosis and none were cisnture wearers. Twenty-eight isolates were recovered from the oral cavities of individual $\mathrm{HIV}^{+}$patients attending the Dublin Dental Hospital. All of these patients presented with overt clinical symptoms of erythematous or pseudomembranous candidosis, the clinical features and incidence of which have been described by Samaranayake \& Holmstrup (1989). None of the control subjects or HIV ${ }^{+}$patients had been treated with antifungal drugs or antibiotics for one month prior to presentation. Nine $(\sim 32 \%)$ of the 28 isolates from $\mathrm{HIV}^{+}$patients exhibited variation in colony morphology on primary isolation. From three of these, further independent derivatives exhibiting highfrequency switching of colony morphology were recovered in vitro following growth on nutrient-depleted medium (see below). Prior to these experiments, the parental isolates were single-colony purified ten times to eliminate the possibility of multiple strains being present. These derivatives were included in the study because this procedure ensured that they originated from a single strain. $C$. albicans cell counts were performed with diluted yeast suspensions freshly prepared in sterile water using an Improved Neubauer haemocytometer (Hudson \& Hay, 1989).

Chemicals, enzymes, radioisotopes and antifungal drugs. Chemicals and enzymes were purchased from Sigma, $\mathrm{BDH}$ or Boehringer Mannheim. [U-14 C]Acetate (sodium salt; $52 \mathrm{mCi} \mathrm{mmol}^{-1} ; 1.92 \mathrm{GBq}$ $\mathrm{mmol}^{-1}$ ), $R S-\left[2^{-14} \mathrm{C}\right] \mathrm{mevalonic}$ acid (dibenzylethylenediamine salt;

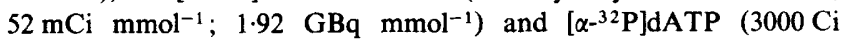


$\mathrm{mmol}^{-1} ; 110 \mathrm{TBq} \mathrm{mmol}^{-1}$ ) were purchased from Amersham. Ketoconazole was a gift from Janssen Pharmaceutical (Cork, Ireland) and fluconazole was a gift from Pfizer Central Research (Sandwich, Kent, UK). Stock solutions ( $1 \mathrm{~mm}$ ) of ketoconazole and fluconazole were prepared in $0.2 \mathrm{M}-\mathrm{HCl}$ and in water, respectively. For azolesusceptibility testing experiments, dilutions of the respective drugs were made in distilled water immediately prior to use and sterilized by filtration through $0.22 \mu \mathrm{m}$ pore diameter membrane filters (Gelman). Protein concentrations in supernatant fractions following homogenization of C. albicans cells were determined using a Bio-Rad Protein Assay kit with bovine albumin as the standard.

Isolation of morphological variants of C. albicans by nutrient depletion. Colony morphology variants of the $C$. albicans oral isolates $122 \mathrm{~A}, 132 \mathrm{~A}$ and $179 \mathrm{~A}$ (all isolated from separate $\mathrm{HIV}^{+}$patients) were recovered following growth in nutrient-depleted medium. YPD broth cultures $(5 \mathrm{ml})$ of each organism were grown for $24 \mathrm{~h}$ at $37^{\circ} \mathrm{C}$ and $1 \times 10^{3}$ c.f.u. used to inoculate modified YPD medium $(5 \mathrm{ml}$; YPD with the nutrient components diluted by a factor of 100 or 200 ), pre-warmed to $37^{\circ} \mathrm{C}$, followed by incubation at $37^{\circ} \mathrm{C}$ for $48 \mathrm{~h}$ in an orbital incubator at 150 r.p.m. After incubation, cultures were resuspended in sterile water at a cell density of $1 \times 10^{3}$ c.f.u. $\mathrm{ml}^{-1}$ and $200 \mu \mathrm{l}$ aliquots plated onto six PDA and six PDAB agar plates, followed by incubation at $37^{\circ} \mathrm{C}$ for $48 \mathrm{~h}$. PDA and PDAB plates were prepared in $9 \mathrm{~cm}$ Petri plates and contained $20 \mathrm{ml}$ of agar per plate. Following incubation, plates were examined for colony morphology variants. Several variant colonies generated from each of the original isolates were chosen for further study.

Azole susceptibility tests. C. albicans clinical isolates and switched derivatives exhibiting colony morphology variation were assessed for their susceptibility to ketoconazole by a hyphal elongation assessment test using an $\mathrm{N}$-acetylglucosamine-yeast nitrogen base-proline (NYP) medium (Marichal et al., 1986). This medium promotes growth in the hyphal form in a humidified atmosphere of $10 \%(\mathrm{v} / \mathrm{v}) \mathrm{CO}_{2}$ at $37^{\circ} \mathrm{C}$. The procedure exploits the differential effect of azole antifungal agents on the growth and morphology of the dimorphic yeast $C$. albicans. In susceptible strains, inhibition of hyphal outgrowth is observed at lower concentrations $(0.0625-0.125 \mu \mathrm{M})$ than with less susceptible strains $(\geq 10 \mu \mathrm{M})$. In susceptible strains only blastoconidia are observed at drug concentrations $>0.125 \mu \mathrm{M}$.

Incorporation of $\left[{ }^{14} \mathrm{C}\right]$ acetate into sterols and lipids by C. albicans whole cells in vitro. The abilities of ketoconazole and fluconazole to affect the incorporation of $\left[{ }^{14} \mathrm{C}\right]$ acetate into sterols and lipids in vitro by whole cells of C. albicans strain 132A and its switched derivative 132ACR were determined by the method described by Van Den Bossche et al. (1978) with the following modifications. Separate 1 litre conical flasks containing $250 \mathrm{ml}$ YEPD broth supplemented with $2.5 \mu \mathrm{mol}$ sodium acetate and $6 \cdot 25 \mu \mathrm{Ci}$ sodium [U-14 C]acetate $\left(52 \mathrm{mCi} \mathrm{mmol}^{-1}\right)$, with or without azole drugs, were inoculated with $C$. albicans strain 132A or its derivative $132 \mathrm{ACR}$ to yield a cell density of $4 \times 10^{4}$ c.f.u. $\mathrm{ml}^{-1}$ and placed in an orbital incubator for $20 \mathrm{~h}$ at $37^{\circ} \mathrm{C}$, after which time the organisms were in late exponential phase with a cell density of approximately $1 \times 10^{8}$ c.f.u. $\mathrm{ml}^{-1}$. The inocula were prepared by diluting cells from $4 \mathrm{~h}$ YEPD broth cultures in sterile saline to yield the required cell density. Cells were homogenized in a Braun cell homogenizer (model MSK; 4000 r.p.m.) using $12 \times 20$ s cycles with $10 \mathrm{~s}$ intermittent cooling using liquid $\mathrm{CO}_{2}$.

Hydrofluor (National Diagnostics) was used as the scintillation fluid and the radioactivity in each sample was measured using a Packard Tri-Carb Liquid Scintillation 1500 spectrometer.

HPLC analysis of sterols from C. albicans whole cells. ${ }^{14} \mathrm{C}$-labelled sterols isolated from C. albicans whole cells, treated or not treated with azole drugs, were analysed by high-performance liquid chromatography (HPLC) as described by Van Den Bossche et al. (1990).
Incorporation of $\left[{ }^{14} \mathrm{C}\right]$ mevalonic acid into sterols synthesized in vitro using $C$. albicans cell-free extracts. The ability of ketoconazole and fluconazole to affect the incorporation of $\left[{ }^{14} \mathrm{C}\right]$ mevalonic acid into sterols synthesized in vitro by cytochrome $P$-450-containing cell-free extracts of C. albicans strain 132A and its switched derivative 132ACR, and of a $C$. albicans fluconazole susceptibility testing reference strain Y0109 (obtained from Dr P. Troke, Pfizer Central Research, Sandwich, Kent, UK), was determined using a modification of the method described by Marriott (1980). Yeast cell suspensions prepared in $12 \mathrm{ml}\left(2 \times 10^{9}\right.$ c.f.u. $\left.\mathrm{ml}^{-1}\right) 100 \mathrm{mM}$-potassium phosphate buffer (pH 7.4) containing $30 \mathrm{~mm}$-nicotinamide, $5 \mathrm{~mm}$ - $\mathrm{N}$-acetylcysteine, $5 \mathrm{mM}-\mathrm{MgCl}_{2}$ and $0.25 \mathrm{~mm}$-phenylmethylsulphonyl fluoride were lysed using $12 \mathrm{~g}$ glass beads $(0 \cdot 45-0.5 \mathrm{~mm})$ in a Braun homogenizer (MSK) using a cycle of $6 \times 20 \mathrm{~s}$ with $10 \mathrm{~s}$ intermittent cooling with liquid $\mathrm{CO}_{2}$. The homogenate was separated from the glass beads, unbroken cells and cell debris by centrifugation for $5 \mathrm{~min}$ at $1500 \mathrm{~g}$. The resulting cellfree homogenate $\left(11 \mathrm{mg}\right.$ protein $\mathrm{ml}^{-1}$ ) was used as the enzymecontaining preparation for in vitro sterol biosynthesis.

The assay mixture for measuring sterol biosynthesis contained $0.5 \mu \mathrm{Ci}\left[2{ }^{-14} \mathrm{C}\right]$ mevalonic acid $\left(52 \mathrm{mCi} \mathrm{mmol}^{-1}\right)$ and the cofactor solution in addition contained $1 \mu \mathrm{mol}$ NADPH.

Samples $(100 \mu \mathrm{l})$ were removed for assay of total ${ }^{14} \mathrm{C}$-incorporation by liquid scintillation counting. The remaining solution was concentrated to dryness and the sterols redissolved in $0.5 \mathrm{ml}$ ethyl acetate. Aliquots $(40 \mu \mathrm{l})$ were applied $2 \mathrm{~cm}$ from the bottom of silica gel $\mathrm{F}_{254}$ pre-coated aluminium TLC plates $(0.20 \mathrm{~mm}$ thick, $20 \times 20 \mathrm{~cm}$; Merck no. 5554) and the sterols and sterol precursors separated using a toluene/diethyl ether $(9: 1, \mathrm{v} / \mathrm{v})$ solvent system (Hitchcock et al., 1989). Following chromatography, sterol bands were located by exposing the TLC plates to UV light $(345 \mathrm{~nm})$ both before and after spraying the plates with the autoradiographic image intensifier Autofluor (National Diagnostics). Radioactive bands were located by autoradiography following exposure of TLC plates to Hyperfilm- $\beta \max$ (Amersham). Sterol-containing bands were then scraped from the TLC plates and levels of ${ }^{14} \mathrm{C}$-incorporation measured by scintillation counting as described above. Unlabelled squalene, lanosterol and ergosterol $(40 \mu \mathrm{l}$ of $0.75 \%, w / v$, solutions in ethyl acetate) were applied to all TLC plates as control standards (Barrett-Bee et al., 1986).

Molecular fingerprinting of C. albicans genomic DNA. Total cellular DNA from $C$. albicans isolates and colony morphology variants was isolated using a modification of the methods described by Durkaez et al. (1985) and Pearce \& Howell (1991) as follows. After RNAase treatment of the extracted DNA, proteinase $\mathrm{K}$ was added to a final concentration of $2 \mathrm{mg} \mathrm{ml}^{-1}$ followed by incubation at $37^{\circ} \mathrm{C}$ for $2 \mathrm{~h}$. The DNA was then precipitated with 2 vols ethanol at $-70^{\circ} \mathrm{C}$ for $1 \mathrm{~h}$, and the precipitate was recovered by centrifugation in a microfuge, washed gently with $100 \mu \mathrm{l} 70 \%(\mathrm{v} / \mathrm{v})$ ethanol, dried and resuspended in TE buffer (10 mM-Tris/HCl, 1 mM-EDTA, pH 7.0). This solution was then extracted once with an equal volume of phenol/chloroform $(1: 1, \mathrm{v} / \mathrm{v})$ and the resulting DNA-containing extract used directly in restriction endonuclease digestion experiments.

The procedures used for restriction endonuclease digestion of genomic DNA, agarose gel electrophoresis, Southern hybridization analysis, labelling of molecular probes with $\left[\alpha^{-32}\right.$ P $]$ dATP and autoradiography have all been described previously (Coleman et al., 1986, 1989).

A C. albicans-specific DNA fragment cloned from dispersed, repetitive sequence DNA was used as a molecular probe in hybridization experiments. The probe consisted of a $3.0 \mathrm{~kb}$ EcoRI fragment cloned in vector plasmid pUC18, and was identical to probe 27A described by Scherer \& Stevens (1988). Escherichia coli strain 824 (strain JM83 harbouring pUC18 containing the cloned $3.0 \mathrm{~kb}$ EcoRI insert) was obtained from Professor S. Scherer (Minnesota, Minneapolis, USA). 


\section{Results}

Susceptibility of oral isolates of C. albicans and colony morphology variants to ketoconazole

In order to determine the susceptibility of oral isolates of C. albicans from Irish $\mathrm{HIV}^{+}$patients to azole antifungals, 28 isolates from separate $\mathrm{HIV}^{+}$individuals were tested for their sensitivity to ketoconazole using a hyphal elongation assessment test. The susceptibility of these isolates was compared with that of oral carriage strains from 12 healthy individuals and also with that of several derivatives of isolates from $\mathrm{HIV}^{+}$patients, recovered in vitro by culturing the parental organisms in nutrientdepleted medium, which exhibited colony morphology variation or switching. The vast majority $(11 / 12)$ of the control carriage isolates were susceptible to ketoconazole, whereas about half $(15 / 28)$ of the isolates from $\mathrm{HIV}^{+}$patients exhibited lower susceptibility (Table 1 ).

Nine $(32 \%)$ of these isolates from $\mathrm{HIV}^{+}$patients exhibited variation in colony morphology on primary isolation. In the case of six isolates, the colonies varied between two colony morphology phenotypes, whereas the remaining three isolates switched between three colony morphology phenotypes. To ensure that mixed strains were not responsible for the observed colony morphology variation, total cellular DNA from representative colonies of each phenotype, for all nine isolates, was recovered, digested with the restriction endonuclease $E c o$ RI and hybridized with a ${ }^{32} \mathrm{P}$-labelled mid-repeat sequence probe identical to 27A (Scherer \& Stevens, 1988). The probe was $C$. albicans-specific, with several copies dispersed throughout the genome. When total
Table 1. Susceptibility of oral C. albicans isolates from healthy carriers and $\mathrm{HIV}^{+}$patients to ketoconazole determined by hyphal elongation assessment

\begin{tabular}{lccc}
\hline \hline \multicolumn{1}{c}{ Isolate } & $\begin{array}{c}\text { No. of } \\
\text { source }\end{array}$ & $\begin{array}{c}\text { No. of isolates } \\
\text { with high } \\
\text { susceptibility* }\end{array}$ & $\begin{array}{c}\text { No. of isolates } \\
\text { with low } \\
\text { susceptibility } \dagger\end{array}$ \\
\hline Healthy carriers & 12 & 11 & 1 \\
HIV ${ }^{+}$patients & 28 & 13 & 15 \\
\hline \hline
\end{tabular}

* Hyphal outgrowth inhibited in the presence of ketoconazole concentrations in the range $0.0625-0.125 \mu \mathrm{M}$.

$\dagger$ Hyphal outgrowth inhibited only in the presence of ketoconazole concentrations $\geq 10 \mu \mathrm{M}$.

cellular DNA from the $C$. albicans isolates was digested and hybridized with the probe, the resulting multiple fragments detected following autoradiography constituted molecular 'fingerprint' patterns which could be used to distinguish between different strains (Scherer \& Stevens, 1988; Fox et al., 1989). The molecular fingerprints of all nine isolates were clearly different from each other, whereas the fingerprints of spontaneous variant colonies of the same clinical isolate were in each case indistinguishable (data not shown). Fingerprint patterns generated with cloned, repeat sequence probes can readily distinguish between different strains of $C$. albicans but fingerprints of switched derivatives of a particular strain tend to yield indistinguishable patterns (Soll et al., 1987; Scherer \& Stevens, 1988). These findings confirmed that the observed phenomenon of colony morphology variation by the nine oral isolates from $\mathrm{HIV}^{+}$patients was not due to mixed strains. Of

Table 2. Susceptibility of oral C. albicans isolates from $\mathrm{HIV}^{+}$patients and of their derivatives to ketoconazole as determined by hyphal elongation assessment

\begin{tabular}{|c|c|c|c|}
\hline $\begin{array}{c}\text { Isolate/ } \\
\text { derivative }\end{array}$ & $\begin{array}{l}\text { Ketoconazole } \\
\text { susceptibility* }\end{array}$ & $\begin{array}{c}\text { Colony } \\
\text { morphology }\end{array}$ & Comments \\
\hline $132 \mathrm{~A}$ & High & Smooth-white & Oral isolate from $\mathrm{HIV}^{+}$patient \\
\hline $132 \mathrm{~A}-1$ & High & Rough-tan & Spontaneous derivative of $132 \mathrm{~A}$ \\
\hline $132 \mathrm{~A}-2 \dagger$ & High & Rough-tan & Derivative of $132 \mathrm{~A}$ \\
\hline $132 \mathrm{~A}-3 \dagger$ & High & Wrinkled-tan & Derivative of $132 \mathrm{~A}$ \\
\hline 132ACR $†$ & Low & Wrinkled-tan & Derivative of $132 \mathrm{~A}$ \\
\hline 132ACR-1 & Low & Wrinkled-white & Spontaneous derivative of $132 \mathrm{ACR}$ \\
\hline 132ACR-2 & Low & Smooth-white & Spontaneous derivative of $132 \mathrm{ACR}$ \\
\hline $122 \mathrm{~A}$ & High & Smooth-white & Oral isolate from $\mathrm{HIV}^{+}$patient \\
\hline $122 \mathrm{~A}-1+$ & High & Wrinkled-tan & Derivative of $122 \mathrm{~A}$ \\
\hline $179 \mathrm{~A}$ & Low & Smooth-white & Oral isolate from $\mathrm{HIV}^{+}$patient \\
\hline $179 \mathrm{~A}-1 \dagger$ & Low & Wrinkled-tan & Derivative of $179 \mathrm{~A}$ \\
\hline
\end{tabular}

* High susceptibility, hyphal outgrowth inhibited in the presence of ketoconazole concentrations in the range $0.0625-0.125 \mu \mathrm{M}$; low susceptibility, hyphal outgrowth inhibited in the presence of ketoconazole concentrations $\geq 10 \mu \mathrm{M}$.

$\dagger$ Derivatives recovered following growth in nutrient-depleted medium. Three colonies of each organism were tested in separate experiments. 

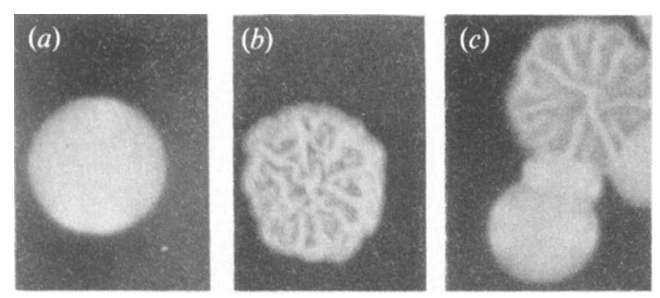

Fig. 1. Colony morphologies of C. albicans isolate $132 \mathrm{~A}$ and its derivative $132 \mathrm{ACR}$ and of colony morphology variants of derivative 132ACR on PDA medium. C. albicans strain 132A (a) was an oral isolate recovered from a $\mathrm{HIV}^{+}$individual. Derivative 132ACR $(b)$ was a tan-coloured wrinkled colony morphology variant derived from strain 132A following growth in nutrient-depleted medium. Derivative 132ACR switches at a frequency of approximately $1 \%$ between three colony morphology phenotypes including tan wrinkled, white wrinkled and smooth white colony forms. Panel (c) shows examples of the white wrinkled and smooth white colony forms.

these nine isolates, six exhibited lower susceptibility to ketoconazole. Two colony morphology phenotypes of each of these six isolates were tested and all exhibited reduced susceptibility to ketoconazole.

Derivatives exhibiting high-frequency switching of colony morphology (colony morphology alternated between two or three colony variant forms at frequencies of approximately $1 \%$, i.e. about 1 in 100 c.f.u. from a single colony would give rise to a variant colony form) were recovered from three of the nine isolates by culturing them in nutrient-depleted medium. All the derivatives tested exhibited similar ketoconazole susceptibility profiles to their respective parental isolates, except for one morphological variant (designated 132ACR) of the ketoconazole-susceptible parental $C$. albicans isolate $132 \mathrm{~A}$, which exhibited decreased ketoconazole susceptibility (Table 2 ).

Colonies of derivative 132ACR were predominantly tan-coloured, possessing wrinkled surfaces on PDA agar, and readily gave rise to a further two types of colony morphology variants on subculture on PDA agar at $37^{\circ} \mathrm{C}$, at frequencies of approximately $1 \%$ (i.e. about 1 in 100 c.f.u. from a single colony of derivative 132ACR would give rise to either colony variant form; Fig. 1). One of these additional variant forms consisted of white wrinkled colonies and the other, of normal smooth white colonies. Several representative single-colony isolates of both of these types of colony morphology variant also exhibited similar decreased susceptibility to ketoconazole (Table 2). Derivative 132ACR continued to shed these two types of variant colony forms following 100 consecutive single-colony purifications on PDA medium at $37^{\circ} \mathrm{C}$.

These findings indicated that colony morphology variation in vitro can, in some cases, lead to generation of derivatives exhibiting decreased ketoconazole susceptibility, as determined by hyphal elongation assessment experiments. Because the reduced ketoconazole susceptibility expressed by derivative 132ACR and its colony morphology variants was not acquired as a result of prior exposure to the drug, it was decided to investigate this phenomenon further. The effects of the azole antifungals ketoconazole and fluconazole were investigated with respect to (i) growth of $132 \mathrm{ACR}$ and its parental strain $132 \mathrm{~A}$, (ii) lipid and sterol patterns of whole cells of both organisms, and (iii) the biosynthesis of sterols in vitro using cytochrome $P$-450-containing cell-free extracts of strain $132 \mathrm{~A}$ and its derivative 132ACR.

\section{Effects of ketoconazole and fluconazole on growth of C. albicans $132 \mathrm{~A}$ and its derivative $132 \mathrm{ACR}$}

Separate YEPD broth cultures of C. albicans strain 132A and its switched derivative $132 \mathrm{ACR}$ containing standardized inocula were incubated for $20 \mathrm{~h}$ at $37^{\circ} \mathrm{C}$ in the presence or absence of varying concentrations of azole. In control experiments without azole the growth of the parental strain 132A was greater than that of its derivative $132 \mathrm{ACR}$ in more than ten separate experiments; following $20 \mathrm{~h}$ growth the cell density of broth cultures of strain $132 \mathrm{~A}$ was 1.4 times greater than cultures of its derivative 132ACR. Ketoconazole had a greater effect in reducing the cell densities of broth cultures of $C$. albicans strain 132A than of broth cultures of its derivative $132 \mathrm{ACR}$ over a range of drug concentrations (Fig. 2a). Thus the cell densities (expressed as a percentage of those of drug-free control cultures) of broth cultures of derivative 132ACR were $5 \%$ greater than those of broth cultures of strain $132 \mathrm{~A}$ at a ketoconazole concentration of $0.01 \mu \mathrm{M}$ and $13 \%$ greater at $0.1 \mu \mathrm{M}$ (Fig. 2a). The cell density of derivative $132 \mathrm{ACR}$ was reduced to $2 \%$ of the control value following growth in the presence of $10 \mu \mathrm{M}$-ketoconazole, whereas that of the parental strain 132A was reduced to $2 \%$ at a ketoconazole concentration of only $0 \cdot 1 \mu \mathrm{M}$. Both organisms were less susceptible to growth inhibition by fluconazole than by ketoconazole over the same concentration range. Derivative 132ACR exhibited a greater susceptibility to fluconazole at the lower azole concentrations $(0 \cdot 1$ and $1.0 \mu \mathrm{M})$ than its parental strain $132 \mathrm{~A}$, whereas it exhibited a decreased susceptibility in comparison to strain $132 \mathrm{~A}$ at $10 \mu \mathrm{M}$-fluconazole (Fig. $2 b)$.

\section{Biosynthesis of lipids and sterols in whole cells of C. albicans strain $132 \mathrm{~A}$ and its derivative $132 \mathrm{ACR}$}

In order to determine the effects of azoles on the biosynthesis of lipids and sterols in whole cells of $C$. albicans strain 132A and its derivative 132ACR, these 

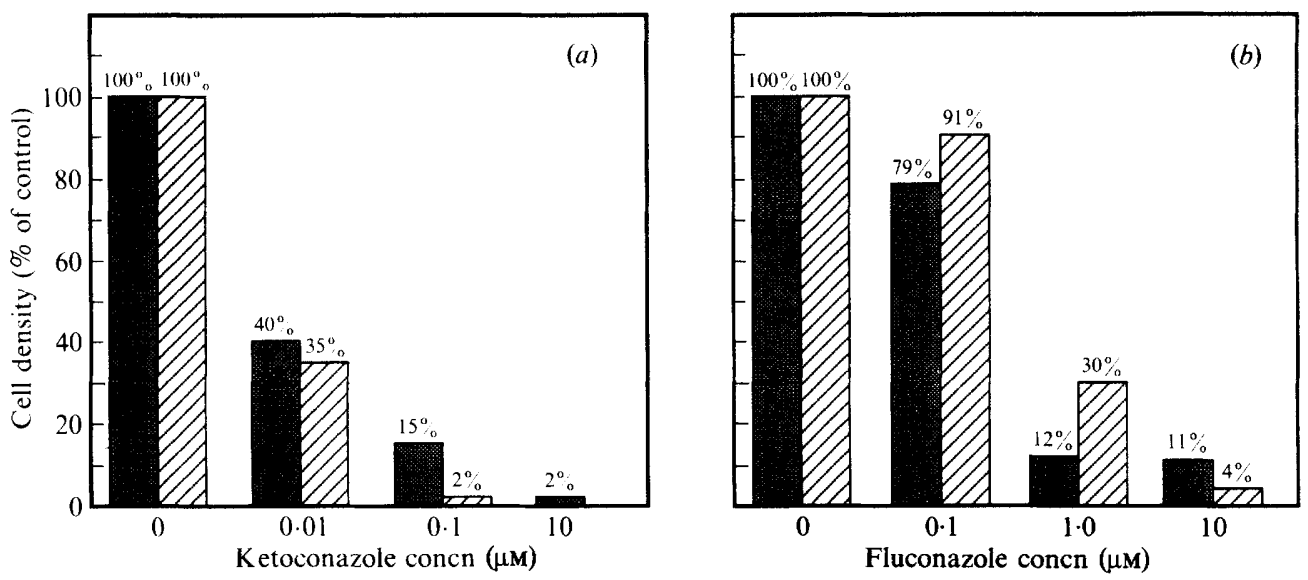

Fig. 2. Cell densities of C. albicans strain 132A ( $)$ and its derivative 132ACR (⿴囗大) following growth in YEPD medium at $37^{\circ} \mathrm{C}$ in the presence and absence of azoles. Cell densities are expressed as a percentage of azole-untreated cultures for each respective organism. For strain $132 \mathrm{~A}$, the mean value for $100 \%(n=3)$ was $13.4 \times 10^{7}$ c.f.u. $\mathrm{ml}^{-1}$ and for derivative $132 \mathrm{ACR}, 9 \cdot 75 \times 10^{7}$ c.f.u. $\mathrm{ml}^{-1}$. $(a)$ Ketoconazole-treated cultures; $(b)$ fluconazole-treated cultures. Similar results were obtained in three separate sets of experiments.

organisms were grown in the presence of $\left[{ }^{14} \mathrm{C}\right]$ acetate and of various concentrations of ketoconazole and fluconazole.

Total lipid extract. An increase in the ${ }^{14} \mathrm{C}$-incorporation into the lipid extracts of strain 132A and its derivative $132 \mathrm{ACR}$ grown for $20 \mathrm{~h}$ in YEPD with $\left[{ }^{14} \mathrm{C}\right]$ acetate was observed with increasing concentrations of both ketoconazole and fluconazole compared with azole-untreated control cultures (Fig. 3). For both drugs, the incorporation of the ${ }^{14} \mathrm{C}$-label was higher by the parental strain $132 \mathrm{~A}$ than by its switched derivative $132 \mathrm{ACR}$, with the greatest difference (approximately 10-fold) observed at $0 \cdot 1 \mu \mathrm{M}$-ketoconazole (Fig. 3). However, gross lipid analysis of strain 132A and its derivative 132ACR by TLC showed no obvious differences (data not shown). The highest ${ }^{14} \mathrm{C}$-incorporation $(38.9 \%)$ was recorded in lipid extracts prepared from $250 \mathrm{ml}$ YEPD broth cultures of strain 132A grown in the presence of $10 \mu \mathrm{M}$ fluconazole and $\left[{ }^{14} \mathrm{C}\right]$ acetate $\left(9 \times 10^{6}\right.$ d.p.m. per $250 \mathrm{ml}$ medium).

Sterols. Incubation of strain $132 \mathrm{~A}$ and its derivative $132 \mathrm{ACR}$ for $20 \mathrm{~h}$ in the presence or absence of ketoconazole or fluconazole or solvent alone and $\left[{ }^{14} \mathrm{C}\right]$ acetate followed by TLC of the lipid fractions demonstrated that almost $75 \%$ and $72 \%$, respectively, of the total ${ }^{14} \mathrm{C}$-label present in the cell extracts was incorporated into complex lipids (Table 3 ). ${ }^{14} \mathrm{C}$-incorporation into free sterols recovered from cultures of strain $132 \mathrm{~A}$ and its derivative $132 \mathrm{ACR}$ represented about $17 \%$ and $19 \%$, respectively, of the total ${ }^{14} \mathrm{C}$-incorporation with organisms grown in the absence of azoles (Table 3). There was no apparent difference in the amount of incorporated ${ }^{14} \mathrm{C}$-label in the ergosterol-containing $\mathrm{C}-4$

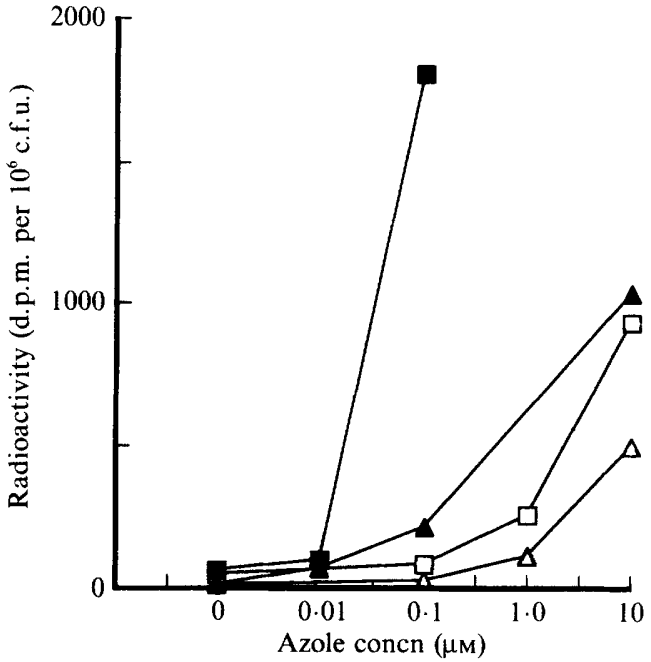

Fig. 3. $\left[{ }^{14} \mathrm{C}\right]$ Acetate incorporation into lipids and sterols in whole cells of C. albicans strain 132A and its derivative 132ACR following $20 \mathrm{~h}$ growth in the presence of $\left[{ }^{14} \mathrm{C}\right]$ acetate and with or without various concentrations of ketoconazole or fluconazole. Insufficient growth of strain $132 \mathrm{~A}$ was obtained in the presence of $10 \mu \mathrm{M}$-ketoconazole for analysis to be performed. $\square$, Strain 132A grown with ketoconazole; $\boldsymbol{\Delta}$, strain 132A grown with fluconazole; $\square$, derivative 132ACR grown with ketoconazole; $\triangle$, derivative 132ACR grown with fluconazole. Similar data were obtained with three separate sets of experiments.

demethyl sterol fractions of azole-untreated control cultures of strain 132A and its derivative 132ACR (Table $3)$. However, clear-cut differences were observed in the ${ }^{14} \mathrm{C}$-levels incorporated into $\mathrm{C}$-4 demethyl, 4,14-dimethyl-, and 4,4'14-trimethyl sterols between control and azole-treated cells of either organism (Table 3). A $50 \%$ decrease in $\left[{ }^{14} \mathrm{C}\right]$ acetate incorporation into the $\mathrm{C}-4$ demethyl sterols fraction was obtained at a ketoconazole concentration of $\sim 0.01 \mu \mathrm{M}$ and a fluconazole concentra- 
Table 3. Effects of ketoconazole and fuconazole on the incorporation of $\left[{ }^{14} \mathrm{C}\right]$ acetate into sterols and complex lipids in vitro by whole cells of $C$. albicans strain $132 \mathrm{~A}$ and its derivative $132 \mathrm{ACR}$

\begin{tabular}{|c|c|c|c|c|c|c|c|c|}
\hline \multirow{3}{*}{$\begin{array}{c}\text { Concn } \\
\text { of azole } \\
(\mu \mathrm{M})\end{array}$} & \multicolumn{8}{|c|}{${ }^{14} \mathrm{C}$-label incorporated as $\%$ of total ${ }^{14} \mathrm{C}$-incorporation into indicated classes of lipids* } \\
\hline & \multicolumn{2}{|c|}{ Complex lipids } & \multicolumn{2}{|c|}{ C-4 demethyl sterols } & \multicolumn{2}{|c|}{ 4,14-dimethyl sterols } & \multicolumn{2}{|c|}{$\begin{array}{l}4,4^{\prime}, 14-\text { trimethyl } \\
\text { sterols }\end{array}$} \\
\hline & $132 \mathrm{~A}$ & 132ACR & $132 \mathrm{~A}$ & 132ACR & $132 \mathrm{~A}$ & 132ACR & $132 \mathrm{~A}$ & 132ACR \\
\hline \multicolumn{9}{|c|}{ Ketoconazole } \\
\hline Control & 75 & 72 & 15 & 15 & 1 & 2 & 1 & 1 \\
\hline 0.01 & 71 & 66 & 9 & 8 & 2 & 3 & 4 & 3 \\
\hline $0 \cdot 1$ & 65 & 68 & 5 & 4 & 5 & 3 & 6 & 5 \\
\hline $10 \cdot 0$ & ND & 46 & ND & 2 & ND & 3 & ND & 4 \\
\hline \multicolumn{9}{|l|}{ Fluconazole } \\
\hline Control & 74 & 71 & 12 & 12 & 1 & 1 & 1 & 2 \\
\hline 0.01 & 75 & 78 & 13 & 11 & 1 & 1 & 1 & 1 \\
\hline $0 \cdot 1$ & 67 & 70 & 6 & 5 & 2 & 2 & 1 & 4 \\
\hline $10-0$ & 64 & 76 & 4 & 2 & 4 & 2 & 3 & 5 \\
\hline
\end{tabular}

ND, Not determined; insufficient growth of strain 132A for analysis. Complex lipids remained at the origin following chromatography.

* Total radioactivity found in the lipids and sterols extracted from whole cells was taken as $100 \%$ for each respective strain. Data are presented for a single set of experiments; similar data were obtained in three independent sets of experiments. $R_{F}$ values of the sterols were determined by reference to the relative mobility of authentic standards ( $R_{F}$ values in parenthesis) as follows : C- 4 demethyl sterols, $(0 \cdot 14) ; 4,14$-dimethyl sterols, $(0 \cdot 20) ; 4,4^{\prime}, 14$-trimethyl sterols $(0 \cdot 22)$.

Table 4. Incorporation of $\left[{ }^{14} \mathrm{C}\right]$ acetate into sterols in whole cells of C. albicans strain $132 \mathrm{~A}$ and its derivative $132 A C R$ in the presence or absence of ketoconazole as detected by HPLC analysis

\begin{tabular}{|c|c|c|c|c|c|c|c|c|c|c|}
\hline \multirow[b]{2}{*}{$\begin{array}{l}\text { C. albicans } \\
\text { strain }\end{array}$} & \multirow[b]{2}{*}{$\begin{array}{l}\text { Ketoconazole } \\
\text { concn }(\mu \mathrm{M})\end{array}$} & \multicolumn{9}{|c|}{${ }^{14} \mathrm{C}$-label incorporated as $\%$ of total ${ }^{14} \mathrm{C}$-label incorporation into indicated sterols and squalene } \\
\hline & & $\begin{array}{l}\text { Sterols \& squalene*: } \\
\text { Retention time: }\end{array}$ & $\begin{array}{c}E \\
6 \cdot 6\end{array}$ & $\begin{array}{c}3,6 \text { diol } \\
8 \cdot 2\end{array}$ & $\begin{array}{l}\text { 14ME } \\
17 \cdot 9\end{array}$ & $\begin{array}{l}4 \mathrm{DE} \\
18 \cdot 9\end{array}$ & $\begin{array}{c}\mathrm{OF} \\
21 \cdot 0\end{array}$ & $\begin{array}{c}\mathrm{L} \\
22 \cdot 2\end{array}$ & $\begin{array}{c}\text { 24MET } \\
24 \cdot 7\end{array}$ & $\begin{array}{c}S \\
40 \cdot 9\end{array}$ \\
\hline \multirow[t]{3}{*}{$132 \mathrm{~A} \dagger$} & Control & & 100 & 0 & 0 & 0 & 0 & 0 & 0 & 0 \\
\hline & 0.01 & & 38 & 26 & 0 & 0 & 3 & 17 & 13 & 3 \\
\hline & $0 \cdot 1$ & & 0 & 36 & 1 & 4 & 12 & 16 & 21 & 9 \\
\hline \multirow{4}{*}{ 132ACR } & Control & & 100 & 0 & 0 & 0 & 0 & 0 & 0 & 0 \\
\hline & 0.01 & & 66 & 3 & 0 & 0 & 0 & 19 & 12 & 0 \\
\hline & 0.1 & & 0 & 28 & 0 & 0 & 23 & 9 & 39 & 0 \\
\hline & $10 \cdot 1$ & & 0 & 81 & 0 & 0 & 8 & 3 & 8 & 0 \\
\hline
\end{tabular}

* Total radioactivity detected in sterol and squalene preparations was taken as $100 \%$. Sterols were characterized on the basis of their retention times $(\mathrm{min})$ as shown in the table. Abbreviations: E, ergosta-5,7-22-trien-3-ol (ergosterol); 3,6 diol, 14-methylenergosta-8,24 (28)-dien-3,6-diol; 14ME, 14-methylergosta-8-24 (28)-dien-3-ol; 4DE, 4,14-dimethylergosta-8,24-dien-3-ol; OF, 4, 14-dimethylergosta8,24 (28)-dien-3-ol; L, 4,4',14-trimethylcholesta-8,24-3-ol; 24MET, lanost-8,24 (28)-dien-3-ol; S, squalene.

$\dagger$ Insufficient growth of strain $132 \mathrm{~A}$ was obtained in the presence of $10 \mu \mathrm{M}$-ketoconazole for analysis to be performed.

tion of $\sim 0 \cdot 1 \mu \mathrm{M}$ for both strain $132 \mathrm{~A}$ and its derivative 132ACR (Table 3). An increased incorporation of ${ }^{14} \mathrm{C}$ label was also observed in the sterol fractions containing 4,14-dimethyl sterols and 4,4',14-trimethyl sterols for both organisms (Table 3).

Greater resolution of the three free sterol bands detected by TLC in extracts from whole cells of strain $132 \mathrm{~A}$ and its derivative $132 \mathrm{ACR}$ following $20 \mathrm{~h}$ growth in the presence of ketoconazole was achieved by HPLC (Table 4). In cells of C. albicans strain 132A after $20 \mathrm{~h}$ growth in the presence of $0 \cdot 01 \mu \mathrm{M}$-ketoconazole, incor- poration of ${ }^{14} \mathrm{C}$-label into ergosterol was reduced to $38 \%$ of the control value, whereas in C. albicans derivative 132ACR incorporation of ${ }^{14} \mathrm{C}$-label into ergosterol was only reduced to $66 \%$ of the control value (Table 4 ).

\section{Biosynthesis of sterols in vitro using cell-free extracts of C. albicans strain $132 \mathrm{~A}$ and its derivative $132 \mathrm{ACR}$}

In order to investigate whether the decreased azole susceptibility exhibited by $C$. albicans derivative 132ACR could be correlated with decreased sensitivity 
of its 14-sterol demethylase, the effects of ketoconazole and fluconazole on the biosynthesis of sterols in vitro were investigated using cell-free extracts of strain $132 \mathrm{~A}$ and its derivative 132ACR. Cell-free extracts of both organisms were prepared by homogenization and the biosynthesis of ${ }^{14} \mathrm{C}$-labelled sterols from $\left[2-{ }^{14} \mathrm{C}\right]$ mevalonic acid as substrate was monitored in the presence and absence of azoles. The proportion of $\left[2-{ }^{14} \mathrm{C}\right] \mathrm{mevalonate}$ incorporated into sterols by lysates of C. albicans strain 132A and its derivative $132 \mathrm{ACR}$ was $31 \%$ and $22 \%$, respectively. Sterols were separated by TLC following isolation of non-saponifible lipids. The identity of the separated sterols was determined by reference to the relative mobilities of authentic standards. Non-saponified lipids synthesized from extracts of both strain 132A and its derivative $132 \mathrm{ACR}$ were separated into the following compounds: C-4 demethylated sterols, 4,14-dimethylated sterols, 4,4',14-trimethylated sterols, an unknown compound and squalene.

In experiments with cell-free extracts from strain $132 \mathrm{~A}, 0.01 \mu \mathrm{M}$-ketoconazole and $0.04 \mu \mathrm{M}$-fluconazole, respectively, inhibited sterol demethylation by $50 \%$ ( $\mathrm{IC}_{50}$ values). The corresponding $\mathrm{IC}_{50}$ values for cell-free extracts of derivative $132 \mathrm{ACR}$ were $0.05 \mu \mathrm{M}$-ketoconazole and $1.0 \mu \mathrm{M}$-fluconazole, respectively. Not only were there differences in the $\mathrm{IC}_{50}$ values between strain $132 \mathrm{~A}$ and its derivative $132 \mathrm{ACR}$ but there were also differences in the $\mathrm{IC}_{50}$ values obtained with ketoconazole and fluconazole. Liquid scintillation counting analysis of ${ }^{14} \mathrm{C}$-label incorporation revealed a concomitant increased incorporation of ${ }^{14} \mathrm{C}$-label into the $4,14-$ demethylated sterols and 4,4',14-trimethylated sterols with lysates from both organisms at azole concentrations above the $\mathrm{IC}_{50}$ values.

For comparison with the results obtained with $C$. albicans strain $132 \mathrm{~A}$, additional $\mathrm{IC}_{50}$ determinations were made with a fluconazole reference test $C$. albicans strain, strain Y0109, whose characteristics have been investigated (P. Troke, personal communication). The results for strain Y0109 were similar to strain $132 \mathrm{~A}: \mathrm{IC}_{50}$ value of $0.01 \mu \mathrm{M}$-ketoconazole and $0.05 \mu \mathrm{M}$-fluconazole.

\section{Discussion}

Oral and oesophageal candidosis in $\mathrm{HIV}^{+}$and AIDS patients is a difficult condition to treat effectively. The introduction of the orally active azole antifungals ketoconazole and fluconazole has produced dramatic improvements in the management of the condition in immunocompromised patients (Fazio et al., 1983; Dupont \& Drouhet, 1988; Epstein, 1990; Larsen, 1990; Hay, 1991). However, even with these drugs, protracted treatment is necessary if remission of infection is to be achieved and sustained (Esposito et al., 1990; Leen et al., 1990; Larsen, 1990). The situation has been compounded by an increasing number of reports of azole resistance in oral isolates of Candida species from $\mathrm{HIV}^{+}$and AIDS patients (Tavitian et al., 1986b; Korting et al., 1988; Warnock et al., 1988; Fox et al., 1991; Kitchen et al., 1991; Fan-Havard et al., 1991).

The majority of C. albicans strains and many isolates of other Candida species have the ability to exhibit colony morphology variation or switching, which recent studies have shown is often associated with genetic variation and which may provide, non-sexual Candida strains with the ability to adapt rapidly in their natural environment (Rustchenko-Bulgac et al., 1990; Rustchenko-Bulgac, 1991; Suzuki et al., 1991; Wickes et al., 1991). This ability may contribute to pathogenicity of the switched derivatives and to the development of derivatives with decreased susceptibility to antifungal drugs (Slutsky et al., 1985; Soll, 1989; Ghannoum et al., 1990). Approximately $30 \%$ of oral isolates of C. albicans recovered from more than 200 individual Irish $\mathrm{HIV}^{+}$and AIDS patients exhibited colony morphology variation at $37^{\circ} \mathrm{C}$ on primary isolation (D. C. Coleman and others, unpublished). In the present study variants were readily generated from several oral $C$. albicans isolates from $\mathrm{HIV}^{+}$patients and one of these was found to exhibit substantially reduced susceptibility to ketoconazole in vitro, in comparison to its parental isolate.

The discussion of the results of these experiments has to account for two interacting sets of variables: those arising from the differences between the parental strain $132 \mathrm{~A}$ and its derivative 132ACR, and those that follow from the differences between the drugs ketoconazole and fluconazole. The results of the whole-cell studies showed that the derivative 132ACR grew less efficiently than its parental strain 132A. The pattern of growth inhibition for the two drugs differed: ketoconazole produced a dose-related effect, with $132 \mathrm{~A}$ being more susceptible than 132ACR, while the pattern obtained with fluconazole was quite different. Derivative 132ACR was more susceptible to the effect of fluconazole at $0 \cdot 1$ and $1 \cdot 0 \mu \mathrm{M}$ than $132 \mathrm{~A}$ and although this pattern was reversed at $10 \mu \mathrm{M}$, it is notable that $132 \mathrm{~A}$ was still able to achieve substantial growth in the presence of fluconazole.

The chromatographic analyses showed that $132 \mathrm{~A}$ and 132ACR produced a similar pattern of lipids and sterols, including ergosterol. Incorporation of $\left[{ }^{14} \mathrm{C}\right]$ acetate in control and azole-treated cultures of both organisms was higher for the parental strain 132A than for the derivative $132 \mathrm{ACR}$, reflecting the more efficient growth of the strain. This parameter was highest in the fluconazole-treated cultures of strain $132 \mathrm{~A}$ and the greatest difference between incorporation into $132 \mathrm{~A}$ and $132 \mathrm{ACR}$ was observed with $0 \cdot 1 \mu \mathrm{M}$-ketoconazole, thus 
paralleling data obtained from the cell growth experiments. The concentration required to reduce ${ }^{14} \mathrm{C}$-label incorporation into $\mathrm{C}-4$ demethyl sterols for ketoconazole $(0.01 \mu \mathrm{M})$ and fluconazole $(0.1 \mu \mathrm{M})$ was the same for both $132 \mathrm{~A}$ and 132ACR. The data from these experiments are of the same magnitude as the data from cell growth studies, both in the comparative activities of the two drugs and in the approximate drug concentrations required to inhibit cell growth by $50 \%$. The pattern of incorporation into the different lipid fractions was consistent with inhibition of ergosterol biosynthesis and the accumulation of precursors.

The results using the cell-free system also showed that in both 132A and 132ACR the synthesis of ergosterol could be inhibited by the two drugs and the increased incorporation into precursors occurred at concentrations above the $\mathrm{IC}_{50}$ values. However, it was notable that the $\mathrm{IC}_{50}$ values for the two organisms differed, with 132A being more sensitive to inhibition than 132ACR, and that ketoconazole was more potent than fluconazole. The parental strain 132A would not seem to be atypical since the results obtained with the fluconazole reference test strain (Y0109) were in line with those for 132A and are similar to data published by Marriott \& Richardson (1987). These results suggest, therefore, that the process of 14-demethylation in 132ACR is less readily inhibited by these two drugs than the corresponding process in $132 \mathrm{~A}$.

The lack of correlation between the $\mathrm{IC}_{50}$ values obtained in the cell-free system (ketoconazole-132ACR: $0.05 \mu \mathrm{M}$; fluconazole-132ACR : $1.0 \mu \mathrm{M}$ ) with the approximate values for $50 \%$ reduction of $\left[{ }^{14} \mathrm{C}\right]$ acetate incorporation into whole cells (ketoconazole-132ACR: $0.01 \mu \mathrm{M}$; fluconazole-132ACR : $0 \cdot 1 \mu \mathrm{M}$ ) and, if the comparison is made, though not strictly valid, with the cell growth experiments then the divergence appears to be enhanced. These results are difficult to explain. A number of factors, whether acting separately or in combination, may be important. The concentrations of azoles in the cell growth and whole-cell experiments are those of drug present in the media and we have no way of knowing how much drug entered the cells and remained there as the active moiety, unlike in the cell-free system. This makes a comparison of the concentrations difficult. However, in the cell-free system the sterol biosynthetic pathway is isolated from the micro-environment from which the entire process from acetate uptake to sterol incorporation in the cell membrane occurs in a highly regulated manner. Given that azoles may act at more than one point in this process it is conceivable that the difference between the cell-free and whole-cell experiments reflects this. Other workers have also reported that there was no correlation between the results obtained with a triazole when using a cell-free system and broth dilution (Hitchcock et al., 1987). The results of the present study do not point to the cell wall of $132 \mathrm{ACR}$ being less permeable to azoles than the wall of $132 \mathrm{~A}$ since they are the opposite of what would be expected in that instance as others have shown (Barrett-Bee et al., 1988). Since 132ACR can switch between three colony morphology phenotypes, it is not possible to know which one or which combination of variants is predominant under specific experimental conditions. But if this type of derivative were to arise in vivo the same situation could obtain.

Derivative 132ACR appears to be resistant to the effects of the imidazole ketoconazole and the triazole fluconazole compared to its parental strain 132A. It does not seem to differ in its gross pattern of lipid and sterol production and the resistance may result from an alteration(s) in the sterol biosynthesis pathway. It is not possible to determine from these experiments whether the resistance is a result of the increased production of enzyme or a change in the target site. The emergence of azole resistance in vivo following protracted treatment has been reported previously and is a major cause for concern (Smith et al., 1986). The development of decreased azole susceptibility in switched variants of C. albicans in the absence of prior exposure to azoles, as demonstrated in this study, could be equally important. Nutrient depletion has been shown to allow the isolation of colony morphology variants from Candida strains both at $25^{\circ} \mathrm{C}$ (Odds \& Merson-Davis, 1989) and at the more physiological temperature of $37^{\circ} \mathrm{C}$ in this study. Levels of oral Candida in $\mathrm{HIV}^{+}$and AIDS patients can be very high (Tylenda et al., 1989; Samaranyake \& Holmstrup, 1989) and it is possible that the prevalence of Candida cells in the oral cavities of these individuals could result in localized environments becoming nutrient-depleted. Such conditions might then provide the necessary stimulus for switching to occur and hence increase the possibility that some derivatives with reduced azole susceptibility be formed. This sequence of events could be one of the main reasons why treatment failure following oral and systemic azole therapy of oral candidosis in $\mathrm{HIV}^{+}$and AIDS patients is being reported more frequently. The consequences, if this is the case, for the treatment of these patients will be of great importance in determining which antifungal drugs should be used and how they should be used.

This work was supported by the Irish Health Research Board Opportunistic Infection in AIDS Unit Programme grant and the Irish Board for Science and Technology (EOLAS). We wish to thank Dr H. Van Den Bossche, Dr P. Marichal, Dr M. Coene and Dr W. Cools, Janssen Pharmaceutica, Beerse, Belgium, for performing the HPLC analysis and Professor S. Scherer, Minnesota, USA, for providing the C. albicans-specific recombinant clone. 


\section{References}

ANDERSON, J. M. \& Soll, D. R. (1987). Unique phenotype of opaque cells in the white-opaque transition of Candida albicans. Journal of Bacteriology 169, 5579-5588.

Barrett-BeE, K. J., LANe, A. C. \& Turner, R. W. (1986). The mode of antifungal action of tolnaftate. Journal of Medical and Veterinary Mycology 24, 155-160.

Barrett-Bee, K. J., Lees, J., Pinder, P., Campbell, J. \& Newboult, L. (1988). Biochemical studies with a novel antifungal agent, ICI 195, 739. In Antifungal Drugs; Annals of the New York Academy of Sciences 544, pp. 231-244. Edited by V. St. Georgiev. New York: New York Academy of Sciences.

BoRGERS, M. (1980). Mechanism of action of antifungal drugs, with special reference to the imidazole derivatives. Reviews of Infectious Diseases 2, 520-534.

Coleman, D. C., Arbuthnott, J. P., Pomeroy, H. \& Birkbeck, T. H. (1986). Cloning and expression in Escherichia coli and Staphylococcus aureus of the beta-lysin determinant from Staphylococcus aureus: evidence that bacteriophage conversion of beta-lysin activity is caused by insertional inactivation of the beta-lysin determinant. Microbial Pathogenesis 1, 549-564.

Coleman, D. C., Sullivan, D. J., Russell, R. J., Arbuthnott, J. P., CAREY, B. F. \& Pomeroy, H. P. (1989). Staphylococcus aureus bacteriophage mediating the simultaneous lysogenic conversion of $\beta$ lysin, staphylokinase and enterotoxin A: molecular mechanism of triple conversion. Journal of General Microbiology 135, 1679-1697.

DUPONT, B. \& DROUHET, E. (1988). Fluconazole in the management of oropharyngeal candidosis in a predominantly HIV antibody-positive group of patients. Journal of Medical and Veterinary Mycology 26, 6771.

Durkaez, B., Beach, D., Hayles, J. \& Nurse, P. (1985). The fission yeast cell cycle control gene $c d c 2$ : structure of the $c d c 2$ region. Molecular and General Genetics 201, 543-545.

EPSTEIN, J. B. (1990). Antifungal therapy in oropharyngeal mycotic infections. Oral Surgery Oral Medicine Oral Pathology 69, 32-41.

Esposito, R., CASTAGNA, A. \& UbERTi-FopPa, C. (1990). Maintenance therapy of oropharyngeal candidiasis in HIV-infected patients with fluconazole. AIDS 4, 1033-1034.

Fan-Havard, P., Capano, D., Smith, S. M., Mangia, A. \& Eng, R. H. K. (1991). Development of resistance in Candida isolates from patients receiving prolonged antifungal therapy. Antimicrobial Agents and Chemotherapy 35, 2302-2305.

Fazio, R. A., Wickremesinghe, P. C. \& Arsura, E. L. (1983) Ketoconazole treatment of Candida esophagitis - a prospective study of 12 cases. Gastroenterology 78, 261-264.

FoX, B. C., Mobley, H. L. T. \& WADE, J. C. (1989). The use of a DNA probe for epidemiological studies of candidiasis in immunocompromised hosts. Journal of Infectious Diseases 159, 488-494

Fox, R., Neal, K. R., Leen, C. L. S., Ellis, M. E. \& Mandal, B. K. M. (1991). Fluconazole resistant candida in AIDS. Journal of Infection 22, 201-204.

Gallagher, P. J., Henman, M. C., Coleman, D. C., Russell, R. J. \& ShanleY, D. B. (1991). Antifungal drug sensitivity of Candida albicans from HIV positive patients. British Journal of Clinical Pharmacology 31, 234P.

Ghannoum, M. A., Swairjo, I. \& Soll, D. R. (1990). Variation in lipid and sterol contents in Candida albicans white and opaque phenotypes. Journal of Medical and Veterinary Mycology 28, 103-115.

Glatt, A. E., ChiRgwin, K. \& Landesmann, S. H. (1988). Treatment of infections associated with human immunodeficiency virus. New England Journal of Medicine 318, 1439-1448.

Gottlieb, M. S., Schroff, R., Schanker, H. M., Weisman, J. D., Fan, P. T., WOlF, R. A. \& SAXoN, A. (1981). Pneumocystis carini pneumonia and mucosal candidosis in previously healthy homosexual men: evidence of a new acquired cellular immunodeficiency. New England Journal of Medicine 305, 1425-1431.

HAY, R. J. (1991). Antifungal therapy and the new azole compounds. Journal of Antimicrobial Chemotherapy 28, Supplement A, 35-46.

Hitchcock, C. A., Barrett-Bee, K. J. \& Russell, N. J. (1987). Inhibition of $14 \alpha$-sterol demethylase activity in Candida albicans
Darlington does not correlate with resistance to azole. Journal of Medical and Veterinary Mycology 25, 329-333.

Hitchcock, C. A., Brown, S. B., Evans, E. G. V. \& Adams, D. J (1989). Cytochrome $P$-450-dependent $14 \alpha$-demethylation of lanosterol in Candida albicans. Biochemical Journal 260, 549-556.

Holmberg, K. \& MeYer, R. D. (1986). Fungal infections in patients with AIDS and AIDS-related complex. Scandinavian Journal of Infectious Diseases 18, 179-192.

Hudson, L. \& HAY, F. C. (1989). The lymphocyte: its role and function. In Practical Immunology, 3rd edn, pp. 86-126. London: Blackwell Scientific Publications.

IWAGUCHI, S. I., Homma, M. \& TanaKa, K. (1990). Variations in the electrophoretic karyotype analysed by the assignment of DNA probes in Candida albicans. Journal of General Microbiology 136, 2433-2442.

Kitchen, V. S., Savage, M. \& Harris, J. R. W. (1991). Candida albicans resistance in AIDS. Journal of Infection 22, 204-205.

Klein, R. S., Harris, C. A., Butkus Small, C., Moll, B., Lesser, M. \& FRIEDLAND, G. H. (1984). Oral candidiasis in high risk patients as the initial manifestation of the acquired immunodeficiency syndrome. New England Journal of Medicine 311, 354-358.

Korting, H. C., Ollert, M., GeORgil, A. \& Fröschl, M. (1988). In vitro susceptibilities and biotypes of Candida albicans isolates from the oral cavities of patients infected with human immunodeficiency virus. Journal of Clinical Microbiology 26, 2626-2631.

LARSEN, R. A. (1990). Azoles and AIDS. Journal of Infectious Diseases 162, 727-730.

LeEn, C. L. S., Dunbar, E. M., Ellis, M. E. \& Mandal, B. K. (1990) Once-weekly fluconazole to prevent recurrence of oropharyngeal candidiasis in patients with AIDS and AIDS-related complex: a double-blind placebo-controlled study. Journal of Infection 21, 55-60.

MANDAL, B. (1989). AIDS and fungal infections. Journal of Infection 19 199-205.

Marichal, P., Gorrens, J., Van Cutsem, J. \& Van Den Bossche, H (1986). Culture media for the study of the effects of azole derivatives on germ tube formation and hyphal growth of C. albicans. Mykosen 29, 76-81.

MARRIOTT, M. S. (1980). Inhibition of sterol biosynthesis in Candida albicans by imidazole-containing antifungals. Journal of General Microbiology 117, 253-255.

MARRIOTT, M. S. \& RichARDSON, K. (1987). The discovery and mode of action of fluconazole. In Recent Trends in the Discovery, Development and Evaluation of Antifungal Agents, pp. 81-92. Edited by R. A Fromtling. Barcelona: J. R. Prous Science.

MCEACHERN, M. J. \& Hicks, J. B. (1991). Dosage of the smallest chromosome affects both the yeast-hyphal transition and the whiteopaque transition of Candida albicans WO-1. Journal of Bacteriology 173, 7436-7442.

Merz, W. G., Connelly, C. \& Hieter, P. (1988). Variation of electrophoretic karyotypes among clinical isolates of Candida albicans. Journal of Clinical Microbiology 26, 842-845.

OdDs, F. C. \& Merson-Davies, L. A. (1989). Colony variations in Candida species. Mycoses 32, 275-282.

Pearce, M. A. \& Howell, S. A. (1991). Restriction fragment length polymorphism analysis of azole-resistant and azole-susceptible Candida albicans strains. Journal of Clinical Microbiology 29, 13641367

Phelan, J. A., Saltzman, B. R., Friedland, G. H. \& Klein, R. S. (1987). Oral findings in patients with acquired immunodeficiency syndrome. Oral Surgery Oral Medicine Oral Pathology 64, 50-56.

REDFIELD, R. R. \& BURKE, D. S. (1988). HIV infection: the clinical picture. Scientific American 259, 70-80.

Rikkerink, E. H. A., Magee, B. B. \& Magee, P. T. (1988). Opaquewhite phenotype transition: a programmed morphological transition in Candida albicans. Journal of Bacteriology 170, 895-899.

Rustchenko-BulgaC, E. P. (1991). Variations of Candida albicans electrophoretic karyotypes. Journal of Bacteriology 173, 6586-6596.

Rustchenko-Bulgac, E. P., Sherman, F. \& Hicks, J. B. (1990). Chromosomal rearrangements associated with morphological mutants provide a means for genetic variation of Candida albicans. Journal of Bacteriology 172, 1276-1283. 
Samaranayake, L. P. (1990). Oral candidosis: an old disease in new guises. Dental Update 17, 36-38.

Samaranayake, L. P. \& Holmstrup, P. (1989). Oral candidiasis and human immunodeficiency virus infection. Journal of Oral Pathology and Medicine 18, 554-564.

Scherer, S. \& SteVens, D. A. (1988). A Candida albicans dispersed, repeated gene family and its epidemiologic applications. Proceedings of the National Academy of Sciences of the United States of America 85, $1452-1456$.

SlutSKy, B., Buffo, J. \& Soll, D. R. (1985). High frequency switching of colony morphology in Candida albicans. Science 230, 666-669.

Smith, K. J., Warnock, D. W., Kennedy, C. T. C., Johnson, E. M., Hopwood, V., Van Cutsem, J. \& Van Den Bossche, H. (1986). Azole resistance in Candida albicans. Journal of Medical and Veterinary Mycology 24, 133-144.

Soll, D. R. (1989). High-frequency switching in Candida albicans. In Mobile DNA, pp. 791-797. Edited by D. E. Berg \& M. A. Howe. Washington, DC: American Society for Microbiology.

Soll, D. R., Langtimm, C. J., Mcdowel.l, J., Hicks, J. \& Galask, R. (1987). High-frequency switching in Candida strains isolated from vaginitis patients. Journal of Clinical Microbiology 25, 1611-1622.

SuZUKI, T., MiYamaE, Y. \& Ishida, I. (1991). Variation of colony morphology and chromosomal rearrangement in Candida tropicalis pK233. Journal of General Microbiology 137, 161-167.

SyrJanen, S., Valle, S. L. \& Antonen, J. (1988). Oral candidal infection as a sign of HIV infection in homosexual men. Oral Surgery 65, 36-40.

Tavitian, A., Raufman, J-P. \& Rosenthal, L. E. (1986a). Oral candidasis as a marker for esophageal candidasis in the acquired immunodeficiency syndrome. Annals of Internal Medicine 104, 54-55.
Tavitian, A., Raufman, J-P., Rosenthal, L. E., Weber, J., Webber, C. A. \& Dincsoy, H. P. (1986b). Ketoconazole-resistant Candida eosophagitis in patients with acquired immunodeficiency syndrome Gastroenterology 90, 443-445.

Tylenda, C. A., LaRsen, J., Yeh, C.-K., Lane, H. C. \& Fox, P. C. (1989). High levels of oral yeasts in early HIV-1 infection. Journal of Oral Pathology and Medicine 18, 520-524.

Van Den Bossche, H., Willemsens, G., Cools, W., Lauwers, W. F. J. \& LE JEUNE, L. (1978). Biochemical effects of miconazole on fungi. II. Inhibition of ergosterol biosynthesis in Candida albicans. Chemical-Biological Interactions 21, 59-78.

Van Den Bossche, H., Marichal, P., Gorrens, J., Geerts, H. \& JANSSEN, P. (1988). Basis for the search of new antifungal drugs. In Antifungal Drugs; Annals of the New York Academy of Sciences 544, pp. 191-207. Edited by V. St. Georgiev. New York: New York Academy of Sciences.

Van Den Bossche, H., Marichal, P., Gorrens, J., Bellens, D., Coene, M.-C., Lauwers, W., Le June, L., Moereels, H. \& JansSen P. A. J. (1990). Mode of action of antifungals of use in immunocompromised patients. Focus on Candida glabrata and Histoplasma capsulatum. In Mycoses in AIDS Patients, pp. 223-243. Edited by H. Van Den Bossche, D. W. R. Mackenzie, G. Cauwenbergh, J. Van Cutsem, E. Drouhet \& B. Dupont. New York: Plenum Press.

W ARnock, D. W., Burke, J., Cope, N. J., Johnson, E. M., von Fraunhofer, N. A. \& Williams, E. W. (1988). Fluconazole resistance in Candida glabrata. Lancet ii, 1310.

Wickes, B. L., Golin, J. E. \& Kwon-Chung, K. J. (1991). Chromosomal rearrangement in Candida stellatoidea results in a positive effect on phenotype. Infection and Immunity 59, 1762-1771. 